ORIGINAL RESEARCH

\title{
Snowboarding Injuries in Australia: Investigating Risk Factors in Wrist Fractures to Enhance Injury Prevention Strategies
}

\author{
Tracey J. Dickson, PhD; F. Anne Terwiel, MBA \\ From the Center for Tourism Research, Faculty of Business and Government, University of Canberra, Australia (Dr Dickson); School of \\ Tourism, Thompson Rivers University, Kamloops, British Columbia, Canada (Ms Terwiel).
}

\begin{abstract}
Objective.-To investigate risk factors associated with wrist fractures in snowboarders to inform future snowsport safety strategies.

Methods.-A prospective case-control study using a nonprobability convenience sample was conducted with data collected via a respondent-completed questionnaire. Subjects consisted of snowboarders with a snowboard-related injury who presented to one of 10 medical centers and physiotherapy clinics in resort medical centers and gateway communities across the Australian snowsport season in 2007. Those presenting with injuries other than wrist fractures acted as the control.

Results.-The 611 respondents reported 802 injuries $(61.3 \%$ were males and $51.5 \%$ were aged 16-25 years). Protective equipment was worn by $57.0 \%$ of respondents. The main reason for not wearing a wrist guard was that they did not see the need; of these, $12.9 \%$ experienced a wrist fracture. Most injuries occurred on-piste, in a terrain park, or in a lesson. The main mechanism of injury was falling. The major risk factors for wrist fractures were being less than 16 years of age (OR 3.97, CI 2.54-6.22), being in the alpine area for a holiday (OR 2.77, CI 1.47-5.21), and being a first-day snowboard participant (OR 2.02, CI 1.15-3.64). A direct logistic regression indicated that 3 variables had a statistically significant contribution to the model ( being less than 16 years old, being on holidays in the region, and not wearing a wrist guard).

Conclusions.-The key risk factors in this Australian study reflect other international studies, providing a clear market segment for targeted snowsport safety messages: those less than 16 years old, visitors to the alpine regions, and those not wearing wrist guards.
\end{abstract}

Key words: snowboarding, risk factors, risk management, snowsports, injury prevention

\section{Introduction}

This research explores factors that contribute to the risk of wrist fractures for snowboarders in Australia in order to identify targets for injury prevention strategies. ${ }^{1}$ Previous research indicates that snowboarders could make up from $20 \%$ to $50 \%$ of the more than 220,000 Australians over 14 years of age who participate in snowsports each year. ${ }^{2-4}$ International estimates of injury rates in snowsports suggest that there are around three injuries per 1,000 "skier days," ie, participation days. ${ }^{4}$ In Australia there are more than two

Corresponding author: Tracey J. Dickson, PhD, Centre for Tourism Research, Faculty of Business and Government,University of Canberra, University Avenue, Canberra, ACT 2601, Australia (e-mail: tracey. dickson@canberra.edu.au). million "skier days" per year, ${ }^{5}$ which would suggest an estimated 6,000 snowsport related injuries per year in Australia. With the emergence of newer snowsport disciplines, such as snowboarding, there have been changes in the mechanism and types of snowsport injuries. ${ }^{6}$

There is debate over the extent to which wrist guards protect against upper limb injuries. ${ }^{7,8}$ Despite there being evidence that wrist guards may protect against wrist fractures, 2 studies suggest that snowboarders do not see the need to wear wrist guards, and some participants believe that wrist guards will actually contribute to injuries, thus suggesting that snowsport safety messages may not be reaching the target audiences.

A thorough understanding of snowsport injuries will help informational and educational programs aimed at 
targeted snowsport participants. Preventing injuries, particularly severe injuries, mitigates the physical and psychosocial reasons for not returning to the activity. ${ }^{1}$ Something for consideration by resort managers is that as many as $17 \%$ of injuries may involve people working in the snowsport industry, raising concerns about occupational health and safety and the ongoing availability of staff. ${ }^{4}$

The relative newness of snowboarding compared with alpine skiing, and the fact that it is appealing to a market that may possibly be higher risk-takers, ${ }^{9}$ presents a challenge to researchers and those who are responsible for managing snowsport safety. To help inform these groups, this research addresses 3 questions: 1) which snowboarders are most at risk of a wrist fracture?; 2) where and how do most injuries occur?; and, 3) what are the behaviors and attitudes toward protective equipment usage? Answers to these questions will aid in the development of injury prevention and snowsport safety strategies.

\section{Methods}

A prospective case-control study, using a nonprobability convenience sample, was conducted by drawing upon 10 medical centers and physiotherapy practices within and adjacent to 6 of the largest snowsport resorts across 2 states in Australia. The staff in each of these practices volunteered to collect data on injuries sustained by snowboarders on the slopes during the 2007 season. As seen in recent research designs, ${ }^{10,11}$ the case subjects were those people presenting with wrist fractures from snowboarding, while controls were those people presenting with other snowboarding injuries. For this study, an "injury" was deemed to be an on-snow incident requiring medical treatment from the various practices involved.

The anonymous respondent-completed questionnaire was designed to build upon knowledge gained via previous research into snowsport injuries. ${ }^{4,12}$ Collected data included demographics, snowboarding experience levels, levels of instruction, protective equipment usage, and wrist guard design. Respondents provided information regarding their snowboard injury including: the mechanism of injury, time and date, location within the resort where the injury occurred, the location of the injury to the body, and the type of injury.

Data was entered into PASW Statistics 18.0 (IBM Corporation, Summers, NY) for analysis. The prevalence of wrist fractures was explored across the case group and the control group, and $\chi^{2}$ analysis (with Yates Continuity Correction for $2 \times 2$ tables) was conducted. Odds ratios and $95 \%$ CI were calculated for the risk factors identified in previous research: age, ${ }^{13}$ gender, ${ }^{6}$ wrist guard usage, ${ }^{8,14}$ and experience levels. ${ }^{14}$ Additional risk factors that were considered included the reason for being in the snowsport resort region, and participation in previous snowboarding lessons. Direct logistic regression was performed to assess the impact of a number of factors on the likelihood that respondents would experience a wrist fracture. The model contained 4 independent variables (age, days of snowboarding experience, reason for being in the region, and wrist guard usage).

\section{Results}

The 611 snowboarders presented with 802 injuries, including bruising ( $82.1 \%$ of respondents), dislocations $(7.2 \%)$, concussions $(1.8 \%)$, and fractures $(38.2 \%)$. Of the 802 injuries, 108 were wrist fractures $(17.7 \%)$, including 2 cases of bilateral wrist fractures. The age range was 8 to 57 years (mean $=22.1$ years, SD 8.1, mode $=$ 15 years), 270 were males less than 25 years of age $(45.7 \%)$. People with less than 7 days of snowboarding experience were the largest group by experience (239, $39.6 \%$ ) (Table 1). Less than half of the respondents indicated that they normally wore at least one piece of protective equipment (49.6\%), as distinct from what they were wearing at the time of their injury. Almost half of respondents had experienced a previous snowboard injury $(265,46.5 \%$, mean injuries $=2.1$, mode $=0)$. Significant differences emerged between the cases and controls in age and snowboard experience (Table 1) with the cases (ie, those with a wrist fracture) being generally younger and less experienced than the controls.

For the 457 (74.8\%) who indicated that they did not normally wear wrist guards when they were snowboarding, the main reasons (using categories from previous research) ${ }^{15,16}$ were: 155 did not see the need $(33.9 \%)$, 111 indicated the wrist guards were uncomfortable to wear $(24.3 \%), 66$ were not able to obtain them (14.4\%), 57 believed that wrist guards would contribute to injuries $(12.5 \%)$, and 38 did not believe they would provide protection $(8.3 \%)$. Of the 155 who did not see the need for wearing wrist guards, 20 (12.9\%) experienced a wrist fracture; of the 38 who thought that wrist guards would not provide protection, $3(7.9 \%)$ experienced a wrist fracture; and of the 57 who believed that wrist guards would contribute to injury, $6(10.5 \%)$ experienced a wrist fracture.

The main location of the respondents at the time of their injury was "on-piste," which is a maintained area within resort boundaries (Table 2). Of the 33 who indicated that they were injured on a terrain park box or rail, 18 (54.5\%) were aged 16 to 25 years; of the 33 who were injured going over a terrain park kicker or jump, 22 (66.7\%) were aged 16 
Table 1. Characteristics of case and control groups

\begin{tabular}{|c|c|c|c|c|}
\hline & $\begin{array}{l}\text { All responses } \\
\quad(n=611)\end{array}$ & $\begin{array}{c}\text { Cases: Wrist Fracture } \\
(n=108)\end{array}$ & $\begin{array}{l}\text { Controls: No Wrist } \\
\text { Fracture }(n=503)\end{array}$ & $\begin{array}{l}\text { Chi-squared Analysis } \\
\quad(d f, N), P \text { value }\end{array}$ \\
\hline Gender & & & & $(1,594), P=.33$ \\
\hline Male & $364(61.3 \%)$ & $60(56.6 \%)$ & $304(62.3 \%)$ & \\
\hline Female & $230(38.7 \%)$ & $46(43.4 \%)$ & $184(37.7 \%)$ & \\
\hline Age group (years) & & & & $(3,599), P<.01$ \\
\hline$<16$ & $133(22.2 \%)$ & $48(45.3 \%)$ & $85(17.2 \%)$ & \\
\hline $16-25$ & $307(51.3 \%)$ & $44(41.5 \%)$ & $263(53.3 \%)$ & \\
\hline $26-40$ & $138(23.0 \%)$ & $14(13.2 \%)$ & $124(25.2 \%)$ & \\
\hline$>40$ & $21(3.5 \%)$ & $0(0.0 \%)$ & $21(4.3 \%)$ & \\
\hline Snowboard experience & & & & $(5,605), P=.02$ \\
\hline 1 day & $67(11.1 \%)$ & $19(17.9 \%)$ & $48(9.6 \%)$ & \\
\hline $2-6$ days & $172(28.4 \%)$ & $34(32.1 \%)$ & $138(27.7 \%)$ & \\
\hline $7-13$ days & $72(11.9 \%)$ & $16(15.1 \%)$ & $56(11.2 \%)$ & \\
\hline 14-27 days & $85(14.0 \%)$ & $14(13.2 \%)$ & $71(14.2 \%)$ & \\
\hline 4-8 weeks & $65(10.7 \%)$ & $6(5.7 \%)$ & $59(11.8 \%)$ & \\
\hline$>8$ weeks & $144(23.8 \%)$ & $17(16.0 \%)$ & $127(25.5 \%)$ & \\
\hline Snowboard lessons & & & & $(4,604), P=.07$ \\
\hline No lessons & $129(21.4 \%)$ & $20(19.0 \%)$ & $109(21.8 \%)$ & \\
\hline $1-5$ & $364(60.3 \%)$ & $310(60.3 \%)$ & $63(60.0 \%)$ & \\
\hline $6-10$ & $50(8.3 \%)$ & $12(11.4 \%)$ & $38(7.6 \%)$ & \\
\hline $11-15$ & $16(2.6 \%)$ & $6(5.7 \%)$ & $10(2.0 \%)$ & \\
\hline$>15$ & $45(7.5 \%)$ & $4(3.8 \%)$ & $41(8.2 \%)$ & \\
\hline $\begin{array}{l}\text { Protection worn at time of } \\
\quad \text { injury }\end{array}$ & & & & N/A \\
\hline None & $263(43.0 \%)$ & $59(54.6 \%)$ & $204(40.6 \%)$ & \\
\hline Helmet & $156(25.5 \%)$ & $39(36.1 \%)$ & $117(23.2 \%)$ & \\
\hline Wrist guard & $76(12.4 \%)$ & $10(9.3 \%)$ & $66(13.1 \%)$ & \\
\hline Hip/butt & $14(2.3 \%)$ & $2(1.9 \%)$ & $12(2.4 \%)$ & \\
\hline Back & $2(0.3 \%)$ & $0(0.0 \%)$ & $2(0.4 \%)$ & \\
\hline
\end{tabular}

to 25 years (one person did not indicate their age). Of the 83 people injured in the terrain park, in the half-pipe, or on the slope-style course, 65 were less than 25 years old (78.3\%).

Table 2. Resort location and activity at time of injury where responses were provided $(n=411)$

\begin{tabular}{lc}
\hline & $N$ (\% of cases $*)$ \\
\hline On-piste & $245(67.3 \%)$ \\
Terrain park total & $67(18.4 \%)$ \\
$\quad$ Box or rail & $34(9.3 \%)$ \\
$\quad$ Kicker or jump & $33(9.1 \%)$ \\
During a snowboarding lesson & $42(11.5 \%)$ \\
Off-piste & $17(4.7 \%)$ \\
Own kicker or jump & $15(4.1 \%)$ \\
Slope style course & $12(3.3 \%)$ \\
Half-pipe & $5(1.4 \%)$ \\
One foot out: skating & $5(1.4 \%)$ \\
During a race & $3(0.8 \%)$ \\
\hline
\end{tabular}

* Multiple responses possible.
Of the 42 injured during a snowboarding lesson, 17 (40.5\%) were less than 16 years old.

Mechanisms of injury are listed in Table 3.

Only 286 respondents $(46.8 \%)$ provided information on both their location within the resort at the time of injury as well as the mechanism of their injury. Of these,

Table 3. Mechanism of injury where responses were provided $(\mathrm{n}=352)$

\begin{tabular}{lc}
\hline & $N$ (\% of cases $*)$ \\
\hline I fell over & $250(79.9 \%)$ \\
I was out of control & $33(10.5 \%)$ \\
I was riding or getting off a lift & $24(7.7 \%)$ \\
Someone ran into me & $23(7.3 \%)$ \\
I ran into someone else & $14(4.5 \%)$ \\
I hit a tree or lift & $7(2.2 \%)$ \\
My binding broke or released & $1(0.3 \%)$
\end{tabular}

\footnotetext{
* Multiple responses possible.
} 
Table 4. Odds ratios and $95 \%$ confidence intervals for potential risk factors

\begin{tabular}{|c|c|c|c|}
\hline & Cases $(n=108)$ & Controls $(n=503)$ & \\
\hline \multicolumn{4}{|l|}{ Gender } \\
\hline Male & $60(56.6 \%)$ & $304(62.3 \%)$ & \multirow[t]{2}{*}{$.79(.52$ to 1.21$)$} \\
\hline Female & $46(43.4 \%)$ & $184(37.7 \%)$ & \\
\hline \multicolumn{4}{|l|}{ Age group (years) } \\
\hline$<16$ & $48(45.3 \%)$ & $85(17.2 \%)$ & \multirow[t]{2}{*}{$3.97(2.54$ to 6.22$)$} \\
\hline$>16$ & $58(54.7 \%)$ & $408(82.8 \%)$ & \\
\hline \multicolumn{4}{|l|}{ Snowboard experience } \\
\hline \multicolumn{4}{|l|}{ First timer vs all others } \\
\hline 1 day & $19(17.9 \%)$ & $48(9.7 \%)$ & \multirow[t]{2}{*}{$2.04(1.15$ to 3.64$)$} \\
\hline$>1$ day & $87(82.1 \%)$ & $449(90.3 \%)$ & \\
\hline \multicolumn{4}{|l|}{ Beginners ( $<7$ days) vs others } \\
\hline$<7$ days & $53(50.0 \%)$ & $186(37.4 \%)$ & \multirow[t]{2}{*}{1.67 (1.10 to 2.55$)$} \\
\hline 7 days or more & $53(50.0 \%)$ & $311(62.6 \%)$ & \\
\hline \multicolumn{4}{|c|}{ Wrist guard usage at the time of injury } \\
\hline No & $97(90.7 \%)$ & $438(86.9 \%)$ & \multirow[t]{2}{*}{$1.46(.73$ to 2.95$)$} \\
\hline Yes & $10(9.3 \%)$ & $66(13.1 \%)$ & \\
\hline \multicolumn{4}{|l|}{ Reason for being in alpine region } \\
\hline Holiday & $95(88.8 \%)$ & $369(74.1 \%)$ & \multirow[t]{2}{*}{$2.77(1.47$ to 5.21$)$} \\
\hline Living or working for season & $12(11.2 \%)$ & $129(25.9 \%)$ & \\
\hline \multicolumn{4}{|l|}{ Previous snowboard lessons } \\
\hline No & $20(19.0 \%)$ & $109(21.8 \%)$ & \multirow[t]{2}{*}{$.84(.50$ to 1.43$)$} \\
\hline Yes & $85(81.0 \%)$ & $390(78.2 \%)$ & \\
\hline
\end{tabular}

the most common injury events were falling over onpiste ( $\mathrm{n}=165,57.7 \%$ of responses), being out of control while on-piste $(\mathrm{n}=23,8.0 \%)$, and falling over in a lesson $(\mathrm{n}=22,7.7 \%)$.

Odds ratios and $95 \% \mathrm{CI}$ were calculated for potential risk factors in wrist fractures (Table 4). The most notable risk factors were: being less than 16 years old, being in the alpine area for a holiday, and being a first-time participant.

For the direct logistic regression, the full model containing all predictors was statistically significant, $\chi^{2}(4$, $N=590)=48.432, P<.001$, indicating that the model was able to distinguish between respondents who experienced a wrist fracture and those who did not. The model as a whole explained between $7.9 \%$ (Cox and
Snell R square) and $13.0 \%$ (Nagelkerke R square) of the variance in wrist fractures and correctly classified $82.2 \%$ of cases. As shown in Table 5, only 3 of the independent variables made a unique, statistically significant contribution to the model (age, reason for being in the region, and wearing a wrist guard). The strongest predictor of reporting a wrist fracture was being less than 16 years old, followed by not wearing a wrist guard and being in the region for a holiday/vacation. These results indicate that respondents under the age of 16 were over 3 times more likely to report a wrist fracture than those 16 years old and over.

Wrist guard design was investigated across the design characteristics of the most commonly available wrist

Table 5. Logistic regression predicting likelihood of wrist fracture

\begin{tabular}{|c|c|c|c|c|c|c|c|c|}
\hline & $B$ & S.E. & Wald & $d f$ & $P$ & Odds Ratio & $\begin{array}{l}\text { 95\% CI for Odds } \\
\text { Ratio Lower }\end{array}$ & $\begin{array}{l}95 \% \text { C. for Odds } \\
\text { Ratio Upper }\end{array}$ \\
\hline Age category ( $<16$ years) & 1.280 & .237 & 29.146 & 1 & .000 & 3.595 & 2.259 & 5.722 \\
\hline $\begin{array}{l}\text { Reason for being in the region } \\
\text { (on holidays) }\end{array}$ & .838 & .367 & 5.221 & 1 & .022 & 2.312 & 1.127 & 4.744 \\
\hline $\begin{array}{l}\text { Wearing a wrist guard at the } \\
\text { time of injury }\end{array}$ & .852 & .387 & 4.851 & 1 & .028 & 2.344 & 1.098 & 5.004 \\
\hline Days experience ( $<7$ days) & .282 & .233 & 1.470 & 1 & .225 & 1.326 & .840 & 2.094 \\
\hline Constant & -3.502 & .509 & 47.363 & 1 & .000 & .030 & & \\
\hline
\end{tabular}


Table 6. Wrist guard design and ownership where a wrist guard was worn at time of injury $(n=76)$

\begin{tabular}{|c|c|c|}
\hline & $\begin{array}{c}\text { Cases } \\
\text { (wrist fracture, } \\
n=10)\end{array}$ & $\begin{array}{c}\text { Controls (no } \\
\text { wrist fracture, } \\
n=66)\end{array}$ \\
\hline \multicolumn{3}{|l|}{ Wrist Guard Length } \\
\hline Short & $8(80 \%)$ & $42(64 \%)$ \\
\hline Long & $0(0 \%)$ & $16(24 \%)$ \\
\hline Missing data & $2(20 \%)$ & $8(12 \%)$ \\
\hline \multicolumn{3}{|l|}{$\begin{array}{l}\text { Wrist guard length and } \\
\text { protection }\end{array}$} \\
\hline $\begin{array}{l}\text { Short, palm-side only } \\
\text { protection }\end{array}$ & $5(50 \%)$ & $16(24 \%)$ \\
\hline $\begin{array}{l}\text { Short, dorsal only or palm } \\
\text { and dorsal protection }\end{array}$ & $2(20 \%)$ & $25(38 \%)$ \\
\hline $\begin{array}{l}\text { Long, palm-side only } \\
\text { protection }\end{array}$ & $0(0 \%)$ & $6(9 \%)$ \\
\hline $\begin{array}{l}\text { Long, dorsal only or palm } \\
\text { and dorsal protection }\end{array}$ & $0(0 \%)$ & $8(12 \%)$ \\
\hline Missing data & $3(30 \%)$ & $11(17 \%)$ \\
\hline \multicolumn{3}{|l|}{ Wrist guard stiffness } \\
\hline Soft & $2(20 \%)$ & $2(3 \%)$ \\
\hline Stiff (some flex) & $4(40 \%)$ & $35(53 \%)$ \\
\hline Rigid (no flex) & $4(40 \%)$ & $23(35 \%)$ \\
\hline Missing data & $0(0 \%)$ & $6(9 \%)$ \\
\hline \multicolumn{3}{|l|}{ Wrist guard position } \\
\hline Build into glove/mitten & $1(10 \%)$ & $4(6 \%)$ \\
\hline Inside glove/mitten & $4(40 \%)$ & $20(30 \%)$ \\
\hline Outside glove/mitten & $4(40 \%)$ & $29(44 \%)$ \\
\hline Missing data & $1(10 \%)$ & $13(20 \%)$ \\
\hline \multicolumn{3}{|l|}{ Wrist guard ownership } \\
\hline My own & $2(20 \%)$ & $28(42 \%)$ \\
\hline Borrowed & $1(10 \%)$ & $3(5 \%)$ \\
\hline Rent/hire & $5(50 \%)$ & $26(39 \%)$ \\
\hline Missing data & $2(20 \%)$ & $9(14 \%)$ \\
\hline
\end{tabular}

guards for sale (or for hire/rent), drawing upon descriptors adopted in previous research. ${ }^{12}$ For the 76 people $(12.4 \%)$ who indicated that they were wearing a wrist guard at the time of their injury, 10 experienced a wrist fracture. Where the design data is available, all people who experienced a wrist fracture while wearing a wrist guard $(\mathrm{n}=8)$ were wearing a short wrist guard, with $50 \%$ using a short, palm-side only design. Those with wrist fractures were more likely to have hired/rented their wrist guards than those who did not experience a wrist fracture (50\% cf. 39\%) (Table 6).

As shown in Table 7, the dominant design of wrist guards worn by snowboarders who experienced a wrist fracture was a palm-side-only design (60\%). When considered in conjunction with the length of the wrist guard, the short palm-side design accounted for $50 \%$ of wrist fractures when wearing wrist guards at the time of injury.

\section{Discussion}

\section{WHO IS MOST AT-RISK?}

Of the 611 injured snowboarders, most were males aged 16 to 25 years. Those with less than 7 days experience were the largest group by experience level, comparable with a previous study where $34.8 \%$ of injured snowboarders had less than 7 days experience. ${ }^{4}$ There were 67 who were first-time participants, which was $11.1 \%$ of all responses but $17.8 \%$ of those with a wrist fracture. This information suggests the necessity of targeting safety communication to new or inexperienced, particularly young male, snowboarders.

\section{RESORT LOCATION, ACTIVITY, AND MECHANISM OF INJURY}

The significance of the number of on-piste injuries to snowboarders may be a result of more people being in these areas. It may also be attributable to the fact that most new snowsport participants have yet to develop the skills to participate off-piste. What is not known is to what extent environmental factors such as slope groom-

Table 7. Odds ratios and $95 \%$ confidence intervals for design characteristics of wrist guards used at the time of injury $(\mathrm{n}=76)$

\begin{tabular}{|c|c|c|c|}
\hline & $\begin{array}{c}\text { Cases }(\%) \\
(n=10)\end{array}$ & $\begin{array}{l}\text { Controls }(\%) \\
\quad(n=66)\end{array}$ & $\begin{array}{c}\text { Odds Ratio } \\
(95 \% \text { CI })\end{array}$ \\
\hline \multicolumn{4}{|l|}{ Protection location } \\
\hline Palm-side only design & $6(60 \%)$ & $23(35 \%)$ & $2.28(.58$ to 8.98$)$ \\
\hline Dorsal (rear) or both sides design & $4(40 \%)$ & $35(53 \%)$ & \\
\hline Missing data & 0 & $8(12 \%)$ & \\
\hline \multicolumn{4}{|l|}{ Protection location and wrist guard length: } \\
\hline Short, palm-side only design & $5(50 \%)$ & $16(24 \%)$ & 4.17 (.89 to 19.52$)$ \\
\hline Short or long, dorsal or both sides design & $3(30 \%)$ & $40(61 \%)$ & \\
\hline Missing data & $2(20 \%)$ & $10(15 \%)$ & \\
\hline
\end{tabular}


ing, obstacles, slope angle, trail design, usage, or crowding may have upon injury levels in groomed areas. For example, with well-groomed, open trails, people may travel faster and put themselves at greater risk when they do not have the knowledge or experience to maintain control or predict when they may be in a situation outside their skill level.

Injuries in terrain parks accounted for almost $30 \%$ of the snowboard injuries. Terrain parks, half pipes, and slope-style courses (where 84 of the injuries occurred) are prime attractions for youth, the group with the highest frequency of injury. This indicates that future snowsport safety tactics and strategies may need to be focused toward this group by exploring what, if any, differences exist in snowboarder subcultures that may be leveraged to support injury-prevention strategies. As with the study limitations, in the absence of information on the proportion of snowboarders who use parks versus on-piste, it is not possible to conclude that park injuries are more common than on-piste, it just may simply be that more snowboarders use the parks.

The incidence of injuries during lessons may be explained by the relatively high percentage of new or inexperienced snowboarders taking lessons in snowsport schools. This indicates that snowboard instructors must be armed with injury-prevention information and education that they can use during their lessons and pass along to their students, which could lead to a reduction of injuries during and after lessons.

\section{PROTECTIVE EQUIPMENT USAGE}

Forty-three percent of respondents were not wearing any form of protective equipment at the time of their injury despite there being extensive discussion about the benefits of using protective equipment in snowsports. ${ }^{19-24}$ Low rates of helmet and wrist guard usage give rise to further questions such as whether the role of protective equipment is being effectively conveyed to participants and, secondly, if participants are indeed ignoring the message about the potential protective role of wrist guards and helmets, then why? The fact that many indicated that they did not see the need or that wrist guards would not protect against an injury (or may add to injuries) suggests that there is a communication issue, while the concern about comfort relates to equipment design. This suggests further research directions that may affect the adoption of appropriate protective equipment usage. ${ }^{25}$

\section{RISK FACTORS IN WRIST FRACTURES}

The results presented here (Table 4) support that people under 16 years of age are 4 times more likely to expe- rience a wrist fracture than other age groups. The increased risk of wrist fractures for people under 16 years old raises the concern that injuries may occur in growth plates, resulting in long-term complications and health costs. ${ }^{26}$ The difference in the results from the odds ratio (univariate) when compared to the logistic regression (multivariate) may be a result of the univariate analysis not incorporating the combined influence of the variables, such as age with being in the region for a holiday. In contrast, the multivariate analysis involves multiple variables simultaneously and, thus, considers a broader impact from data, such as the combination of age, not wearing a wrist guard, and being in the region for a holiday.

First-time participants (ie, first day) are twice as likely to experience a wrist fracture than those with more than one day's experience. This suggests that more effective strategies are required to inform first-time participants about how to minimize the risk of a wrist fracture. The results from this study did not support the contribution of gender or of having had previous snowboard lessons as contributing factors to wrist fractures.

Another notable insight from this research is the greater risk faced by those in the alpine region for a holiday or vacation, with tourists being nearly 3 times more likely to experience a wrist fracture when compared with those who live in the region for the season or permanently. Safety communication may need to be placed in locations likely to be frequented by tourists to the area in order to help mitigate this risk factor. It should be recalled that this study does not provide any information on the levels of exposure, or the participation hours, of respondents. For example, it may be assumed that vacationers may participate less during the season than local residents, but it is not possible to conclude that from the available data.

Previous research on the protective value of wrist guards in snowboarding has focused on whether they were used or not, but the reality is that wrist guards vary greatly in design, wearing position, length, and protection location; so far, there is no published research that looks at outcomes based upon these design elements. Not all wrist guards are the same, so it is problematic to conclude that all wrist guards provide the same protection. Our sample size for those wearing wrist guards was too small to draw any conclusions regarding the role of wrist guard design in protection from or contribution to an injury. The wide CIs we observed could be explained if some wrist guard designs protect against injury, while others may contribute to injuries. For example, no one wearing a long, back-of-wrist or both-sides design experienced a wrist fracture. Further research with a larger sample size and more detail of the wrist guard design, 
brands and models, the kind of injury, and the location of the injury (relative to the wrist guard) is needed to explore what, if any, role the different wrist guard designs play in injury prevention.

\section{Study Limitations}

Case-control studies are common when studying sporting injuries; however, case-control studies have "limited power in reliably identifying risk factors because of their retrospective nature and issues relating to the appropriate selection of both cases and controls." ${ }^{17}$ Finch further suggests that no epidemiological study can clarify the direct mechanisms of injury; however, epidemiological studies, including case-control studies, do help provide pointers toward risk factors that may be modified in the future through injury-prevention strategies. ${ }^{17}$ The choice of using control subjects who have injuries other than wrist fractures, as is the situation here, may enhance the matching on case and controls regarding factors such as risk-taking (not explored here), but not with factors such as the mechanism of injury (ie, whether they fell onto an outstretched arm). ${ }^{18}$ The lack of available data indicating the total number of snowsport participants at the sites (ie, the denominator data) is also problematic for a study such as this. Without this data, it is not possible to determine injury rates or to evaluate the impact of snowsport safety strategies over time. A proportionately small number of respondents reported on wrist guard design, leading to a lack of statistically significant odds ratio analysis in this area. Also, as the data was voluntarily collected by staff at each medical practice, there is no method of determining the proportion of the injured population that was surveyed, whether it is a representative sample, if there was selection bias, or what the rate of refusal might have been. The small sample size, especially for those who were wearing wrist guards at the time of the injury, means that it is not possible to generalize these results to other populations.

\section{Conclusion}

Understanding the risk factors which may lead to snowsport injuries can facilitate more effective injury-prevention strategies to assist all participants in managing their injury risk. While based upon a small sample size, the results of this Australian study support previous research that indicates that age, experience, and wrist guard usage are factors related to the risk of snowboard injuries, particularly wrist fractures. The data also suggest that being a tourist to the alpine region is an additional risk factor. Given that some respondents do not think wrist guards protect against injury or that they may add to injury, safety strategies may need to emphasize education for participants in the role and effect of wrist guards. We call for further research wrist guard designs. In addition, more work is needed to determine the efficacy of injury prevention and snowsport safety strategies targeted toward the high-risk groups we have identified.

\section{Acknowledgments}

The authors thank Dr Marc Binet and Dr Mark Zagorksi for advice on wrist guard design descriptors and the questionnaire design.

This project was made possible by the support of the 10 participating medical and physiotherapy practices.

\section{References}

1. Andrew NE, Gabbe BJ, Wolfe R, et al. Twelve-month outcomes of serious orthopaedic sport and active recreation-related injuries admitted to Level 1 Trauma Centers in Melbourne, Australia. Clin J Sport Med. 2008; 18:387-393.

2. Australian Sports Commission. Participation in Exercise, Recreation and Sport, Annual Report 2009. Australian Government; 2010. Available at: http://www.ausport.gov.au/ information/scors/ERASS/exercise,_recreation_and_ sport_survey_past_reports/erass_2009. Accessed January 7, 2010.

3. Dickson TJ. Reduce the injuries, change the culture: Insights from telemarking. J ASTM Interl. 2006;3: 14138-14139.

4. Dickson TJ, Gray TL, Downey G, Saunders J, Newman C. A Profile of Australian snowsport injuries: A snapshot from the Snowy Mountains. J Sport Tourism. 2008; 13:273-295.

5. Australian Ski Areas Association. Australian Resort Statistics: 2000-2009. Available at: http://www. astm.org/DIGITAL_LIBRARY/JOURNALS/JAI/ PAGES/JAI14138.htm. Accessed July 7, 2010.

6. Bladin C, McCrory P, Pogorzelski A. Snowboarding injuries: current trends and future directions. Sports Med. 2004;34:133-139.

7. Hagel B, Pless IB, Goulet C. The effect of wrist guard use on upper-extremity injuries in snowboarders. Am J Epidemiol. 2005;162:149-156.

8. O'Neill DF. Wrist injuries in guarded versus unguarded first time snowboarders. Clin Orthop Relat Res. 2003;409: 91-95.

9. Boldrino C, Dann K. Risk factors in snowboarding. Int J Inj Contr Saf Promot. 1998;5:41-51.

10. Hagel BE, Russell K, Goulet C, Nettel-Aguirre A, Pless IB. Helmet use and risk of neck injury in skiers and snowboarders. Am J Epidemiol. 2010;171:1134-1143.

11. Mueller BA, Cummings P, Rivara FP, Brooks MA, Terasaki $\mathrm{RD}$. Injuries of the head, face, and neck in relation to ski helmet use. Epidemiology. 2008;19:270-276. 
12. Binet MH. French prospective study evaluating the protective role of all kinds of wrist protectors for snowboarding. In: Langran M, ed. Abstract Book: International Society for Skiing Safety, 17th ISSS Symposium, 13th-19th May, 2007. Vol Abstract Book. Aviemore, Scotland: International Society for Skiing Safety, 2007.

13. Hagel BE, Meeuwisse WH, Mohtadi NG, Fick GH. Skiing and snowboarding injuries in the children and adolescents of Southern Alberta. Clin J Sport Med. 1999;9:9-17.

14. Langran M, Selvaraj S. Increased injury risk among firstday skiers, snowboarders, and skiboarders. Am J Sports Med. 2004;32:96-103.

15. Dickson TJ. Behaviors and attitudes towards snowsport safety in Australia. J ASTM Intern. 2008;5:JAI101433. Available at: http://www.astm.org/DIGITAL_LIBRARY/ JOURNALS/JAI/PAGES/JAI101433.htm.

16. Langran M. Snowboard attitudes study. Available at: http://www.ski-injury.com/sas.htm. Accessed February 2, 2005.

17. Finch CF. A new framework for research leading to sports injury prevention. J Sci Med Sport. 2006;9:3-9.

18. Finch CF, Ullah S, McIntosh AS. Combining epidemiology and biomechanics in sports injury prevention research: A new approach for selecting suitable controls. Sports Med. 2011;41:59-72.
19. Hagel B, Pless IB, Goulet C, Platt R, Robitaille Y. The effect of helmet use on injury severity and crash circumstances in skiers and snowboarders. Accid Anal Prev. 2005; 37:103.

20. Hagel BE, Pless IB, Goulet C, Platt RW, Robitaille Y. Effectiveness of helmets in skiers and snowboarders: casecontrol and case crossover study. BMJ. 2005;330:281.

21. Levy AS, Hawkes AP, Rossie GV. Helmets for skiers and snowboarders: An injury prevention program. Health Promot Pract. 2007;8:257-265.

22. Macnab AJ, Smith T, Gagnon FA, Macnab M. Effect of helmet wear on the incidence of head/face and cervical spine injuries in young skiers and snowboarders. Inj Prev. 2002;8:324-327.

23. Russell K, Christie J, Hagel BE. The effect of helmets on the risk of head and neck injuries among skiers and snowboarders: a meta-analysis. CMAJ. 2010;182:333-340.

24. Russell K, Hagel B, Francescutti LH. The effect of wrist guards on wrist and arm injuries among snowboarders: a systematic review. C J Sport Med. 2007;17:145-150.

25. McGlashan AJ, Finch CF. The extent to which behavioural and social sciences theories and models are used in sport injury prevention research. Sports Med. 2010;40:841-858.

26. Caine D, DiFiori J, Maffulli N. Physeal injuries in children's and youth sports: reasons for concern? Br J Sports Med. 2006,40:749-760. 